\title{
A Clean, Simple, and Efficient Synthesis of 2-Substituted Aryl (Indolyl) Kojic Acid Derivatives by Kaolin/Ag Nanocomposite as a Reusable Catalyst: A Green Protocol
}

\author{
Bahareh Sadeghi and Mohammad Reza Shahedi \\ Department of Chemistry, Islamic Azad University, Yazd Branch, P.O. Box 89195-155, Yazd 8916871967, Iran \\ Correspondence should be addressed to Bahareh Sadeghi; bsadeghia@gmail.com
}

Received 20 May 2013; Revised 23 July 2013; Accepted 24 July 2013

Academic Editor: Mallikarjuna Nadagouda

Copyright (C) 2013 B. Sadeghi and M. R. Shahedi. This is an open access article distributed under the Creative Commons Attribution License, which permits unrestricted use, distribution, and reproduction in any medium, provided the original work is properly cited.

Kaolin/Ag nanocomposite (kaolin/Ag nanocomposite) was synthesized in a nanoreactor by the calcination of the precursor at high temperature and was shown to efficiently catalyze the one-pot, three-component reaction of an aromatic aldehyde, kojic acid, and indole derivatives under solvent-free conditions to afford the corresponding 2-substituted aryl (indolyl) kojic acid derivatives in high yield.

\section{Introduction}

Nanocomposite is a new class of composites in which the dimensions of the material are in the order of nanometers. Because of this nanometer size characteristic, nanocomposites possess superior properties than the conventional composites such as thermal stability, high surface areas, and mechanical and catalytic properties [1-3]. Up to now, various nanocomposites were synthesized on the basis of Ag nanoparticles with antibacterial and catalytic activities, including silver-hydroxyapatite, dendrimer-silver complexes, hollow Pt/Ag, and silver-silica nanocomposite [4-7]. In this paper, we used the adsorption layer on the surface of kaolin as reactor to prepare Kaolin/Ag nanocomposite material which had a small average grain size and was well distributed. The prepared composite was characterized using Fourier transform infrared (FT-IR), X-ray diffraction (XRD), and scanning electron microscope (SEM) instruments.

The 3-substituted indole moieties are included in numerous natural products and they are dominant molecules in medicinal chemistry $[8,9]$. On the other hand, kojic acid is also known as an attractive molecule in pharmaceutical chemistry due to its accessibility, potential biological activity, and high reactivity $[10,11]$. Due to the vast medicinal utility of kojic acid and 3-substituted indole derivatives, the introduction of a mild, efficient, and selective method to synthesize these compounds is still needed. In continuation of our investigations of the application of solid acids in organic synthesis [12-16], we have investigated the synthesis of Kaolin/Ag nanocomposite as a catalyst and applied for the synthesis of 2-substituted aryl (indolyl) kojic acid derivatives.

\section{Experimental}

2.1. General. Melting points were determined with an Electro thermal 9100 apparatus. IR spectra were recorded on a Shimadzu IR-470 spectrometer. ${ }^{1} \mathrm{H}$ and ${ }^{13} \mathrm{C}$ NMR spectra were recorded on Bruker DRX-400 Avance Spectrometer for solutions in $\mathrm{CDCl}_{3}$ using TMS as an internal standard. Mass spectra were recorded on a FINNIGAN-MAT 8430 mass spectrometer operating at an ionization potential of $70 \mathrm{eV}$. Elemental analyses were performed using a Costech ECS 4010 CHNS-O analyzer at the analytical laboratory of Science and Research Unit of Islamic Azad University, Iran. The morphologies of the products were observed using SEM of VEGA/TESCAN microscope with an accelerating voltage of $15 \mathrm{kV}$. X-ray diffraction (XRD) patterns were taken on a Rigaku $D=\max -2500$ instrument with $\mathrm{Cu} \mathrm{Ka}$ radiation $(40 \mathrm{kV}, 100 \mathrm{~mA})$ to analyze crystalline structure. The chemicals for this work were purchased from Fluka (Buchs, Switzerland) and were used without further purification. 


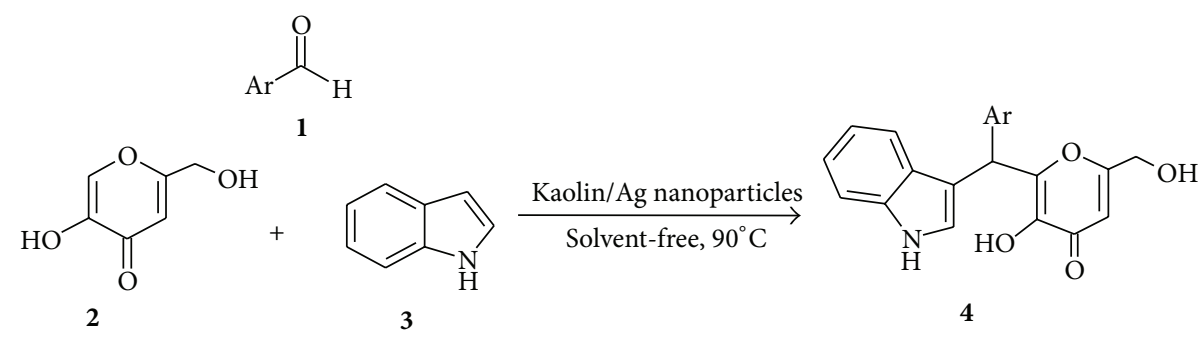

Scheme 1: Synthesis of 2-substituted aryl (indolyl) kojic acid derivatives in the presence of Kaolin/Ag nanocomposite as catalyst.

2.2. General Procedure for the Preparation of Kaolin/Ag Nanocomposite Material. $1.5 \mathrm{~g}$ Kaolin was dried at $90^{\circ} \mathrm{C}$ for $2 \mathrm{~h}$ and cooled at room temperature. Then, $600 \mathrm{~mL}$ of absolute ethyl alcohol was added and well mixed. After $2 \mathrm{~h}$, water $(3 \mathrm{~mL})$ and $\mathrm{NaOH}(0.162 \mathrm{~g})$ were added into the reaction system under stirring and room temperature conditions. After the adsorption equilibrium was attained $(24 \mathrm{~h})$, silver nitrate in water $(100 \mathrm{~mL}$ and $2.28 \mathrm{~g}$ ) was added at a constant rate, react with $\mathrm{NaOH}$, and reduced by ethanol. After reacting for a definite time, the product was gained by centrifugation and dried at room temperature.

2.3. General Procedure for the Preparation of Compounds 4 a$\boldsymbol{m}$. A mixture of aryl aldehyde ( $1 \mathrm{mmol})$, kojic acid ( $1 \mathrm{mmol})$, and Kaolin/Ag NPs (0.001 g) was stirred at $90^{\circ} \mathrm{C}$. After 5$15 \mathrm{~min}$, indole $(1 \mathrm{mmol})$ was added and the reaction was continued for appropriate time. After the completion of the reaction (as monitored by TLC), water was added with reaction mixture $(15 \mathrm{~mL})$ and extracted with ethyl acetate $(3$ $\times 10 \mathrm{~mL}$ ). The organic layer was dried over sodium sulfate and concentrated under vacuum. The crude product was chromatographed in silica gel (70:30n-hexane/ethyl acetate) and appropriate isolated yield.

\section{Results and Discussion}

Herein, we attempted to synthesize Kaolin/Ag nanocomposite in a nanoreactor, which was shown to efficiently catalyse the synthesis of 2-substituted aryl (indolyl) kojic acid derivatives, by the three-component condensation of an aromatic aldehyde $\mathbf{1}$, kojic acid $\mathbf{2}$, and indole derivatives $\mathbf{3}$ (Scheme 1).

The stable catalyst is easily prepared and used for preparation of 2-substituted aryl (indolyl) kojic acid derivatives. The Kaolin/Ag nanocomposite is made using nanotechnique and the mechanism of adsorption. Silver ion is reduced by methanol in an alkaline solution while the temperature was fixed to $25^{\circ} \mathrm{C}$ during the reaction. These are the differences and advantages of this method compared with previous article [17].

In the experiment, we first studied IR spectra of Kaolin and Kaolin/Ag nanocomposite (Figure 1). In both of them, $\mathrm{OH}$ stretching bond is observed at $\sim 3621 \mathrm{~cm}^{-1}$. Comparison of the infrared spectra of Kaolin and Kaolin/Ag show that, in both of them, the asymmetric stretching vibrations for $\mathrm{Al}_{2} \mathrm{O}_{3}$

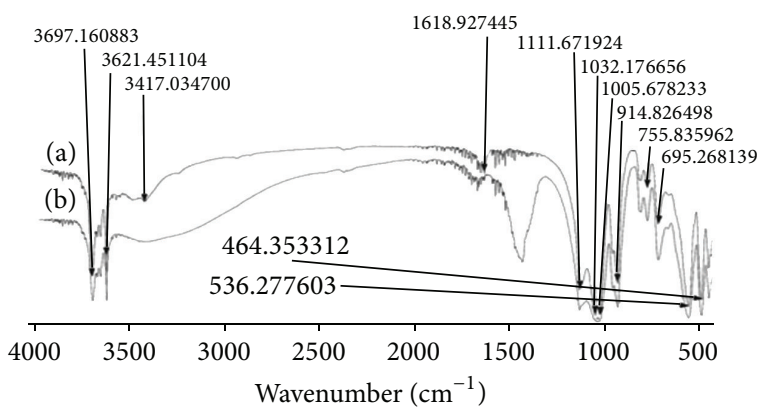

FIGURE 1: FT-IR spectrum of (a) Kaolin and (b) Kaolin/Ag nanocomposite.

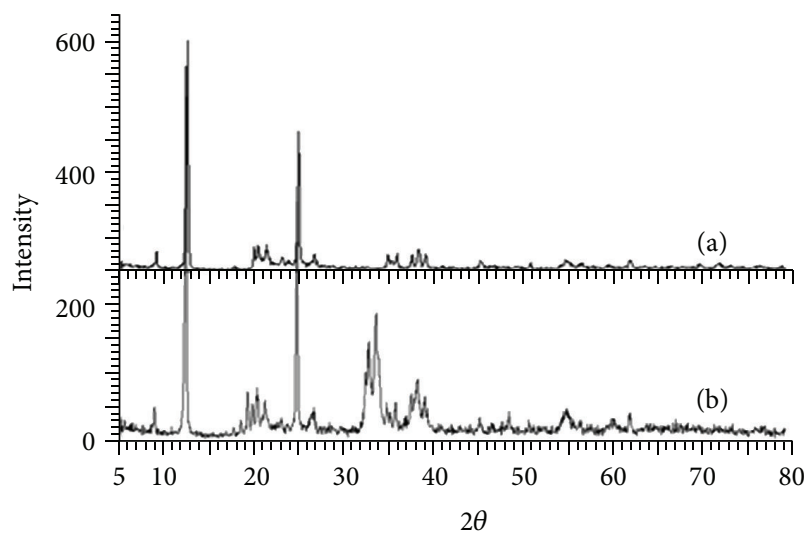

FIGURE 2: XRD patterns of (a) Kaolin and (b) Kaolin/Ag nanocomposite.

and $\mathrm{SiO}_{2}$ appeared at $\sim 914 \mathrm{~cm}^{-1}$ and $\sim 1114 \mathrm{~cm}^{-1}$, respectively. Also, the symmetric stretching vibrations for $\mathrm{Al}_{2} \mathrm{O}_{3}$ and $\mathrm{SiO}_{2}$ appeared at $\sim 694 \mathrm{~cm}^{-1}$ and $\sim 789 \mathrm{~cm}^{-1}$, respectively. In Kaolin/Ag spectrum, the absorption of nitrate is observed at 1369 and $1444 \mathrm{~cm}^{-1}$. It is detected that $\mathrm{Ag}$ nanoparticles are distributed over the surface of Kaolin in the form of massive agglomeration.

The results of XRD are shown in Figure 2. In both XRD patterns, peaks that appeared at $2 \theta=10$ and $25^{\circ}$ are quartz crystals. The pattern of Kaolin (a) shows that at $2 \theta=30-40^{\circ}$ no characteristic peaks come out, but pattern of Kaolin/Ag nanocomposite (b) shows that at $2 \theta=$ 


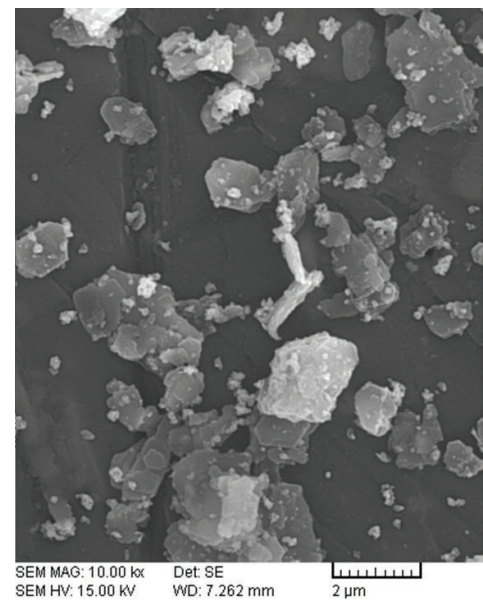

(a)

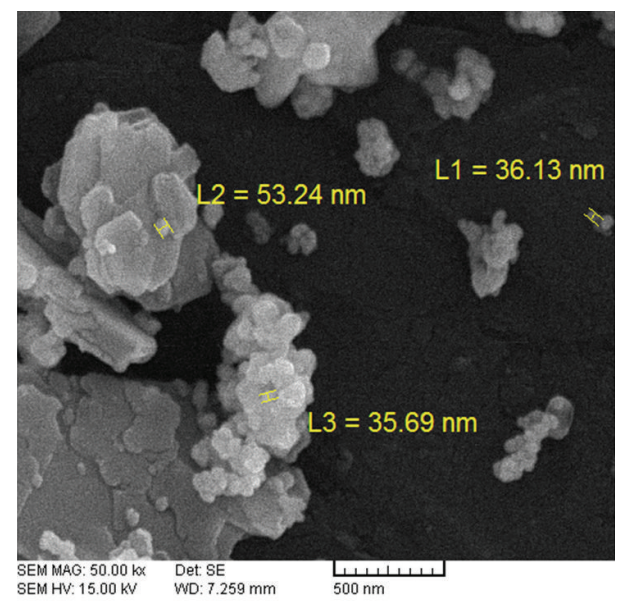

(b)

FIGURE 3: SEM images of Kaolin/Ag nanocomposite.

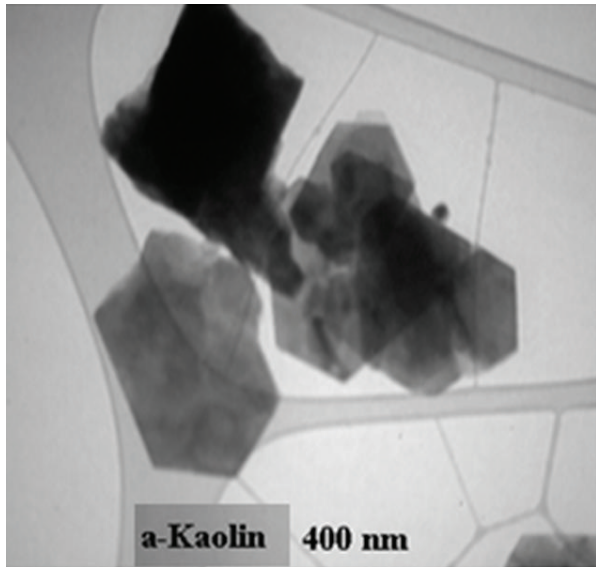

(a)

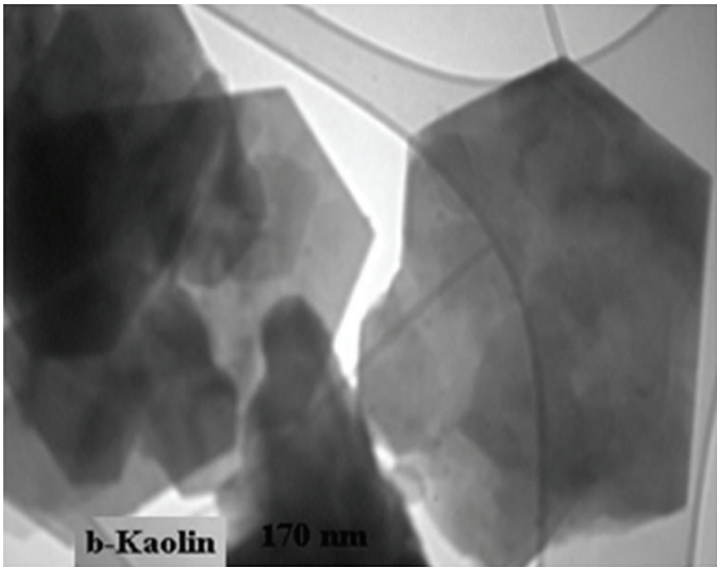

(b)

Figure 4: TEM images of (a) Kaolin $400 \mathrm{~nm}$ and (b) Kaolin $170 \mathrm{~nm}$.

$30-40^{\circ}$ intensities of peaks increase, which demonstrates that Kaolin/Ag nanocomposite is produced.

As reported in the article for silver nanoparticle/kaolinite composites [17], silver is placed in the space between the layers of kaolinite and that explains why the XRD of kaolinite and silver nanoparticle/kaolinite composites are identical.

The dimensions of nanoparticles were observed with SEM. The size of commercial Kaolin/Ag nanocomposite is about 36-53 nm, and SEM images of Kaolin/Ag nanocomposite showed that the Ag nanoparticles were homogeneously dispersed in Kaolin matrices (Figure 3).

It is clearly seen on the TEM images of Kaolin that the crystals' size is $170-400 \mathrm{~nm}$, but TEM images of Kaolin/Ag nanocomposite show crystals' size decrease of $50 \mathrm{~nm}$, and it is detected that $\mathrm{Ag}$ nanoparticles are distributed over the surface of Kaolin in the form of massive agglomeration (Figures 4 and 5).
BET results are given in Table 1 . This information includes the measurement of surface area, total pore volume, and the average pore diameter of Kaolin/Ag nanocomposite and Kaolin. According to the obtained data, weight, surface area, and the average pore diameter of Kaolin/Ag nanocomposite were increased than those of Kaolin and the total pore volume was decreased.

To optimize the reaction conditions, the reaction of benzaldehyde, kojic acid, and indole was used as a model reaction. In order to establish the better catalytic activity of Kaolin/Ag nanocomposite, we have compared the reaction using other catalysts at solvent-free conditions and for $75 \mathrm{~min}$. The results are listed in Table 2. The problems in the reported protocols such as prolonged reaction time and poor yields prompted us to develop a new rapid method affording excellent yield for the synthesis of 2-substituted aryl (indolyl) kojic acid derivatives. 
TABLE 1: Study of BET tests of Kaolin and Kaolin/Ag nanocomposite.

\begin{tabular}{llcc}
\hline Entry & Type of measurement & Kaolin & Silver/kaolin \\
\hline 1 & Sample weight $(\mathrm{g})$ & 0.1527 & 77 \\
2 & Temperature $(\mathrm{k})$ & 77 & 77 \\
3 & Saturated vapor pressure $(\mathrm{KPa})$ & 89.013 & 89.009 \\
4 & Mean pore diameter $(\mathrm{nm})$ & 41.65 & 54.70 \\
5 & Total pore volume $\left(\mathrm{cm}^{3} \cdot \mathrm{g}^{-1}\right)$ & 0.1064 & 0.1013 \\
6 & As, BET $\left(\mathrm{m}^{2} \cdot \mathrm{g}^{-1}\right)$ & 1.02 & 7.41 \\
\hline
\end{tabular}

TABLE 2: Evaluation of the activity of different catalysts for the synthesis of $\mathbf{4 a}$.

\begin{tabular}{llc}
\hline Entry & Catalyst & Yield $^{\mathrm{a}} \%$ \\
\hline 1 & $\mathrm{KAl}\left(\mathrm{SO}_{4}\right)_{2} \cdot 12 \mathrm{H}_{2} \mathrm{O}$ & 60 \\
2 & Kaolin & 83 \\
3 & Silver NPs & 92 \\
4 & Kaolin/Ag nanocomposite & 98 \\
\hline
\end{tabular}

${ }^{\mathrm{a}}$ Reaction conditions: $60 \mathrm{~min}$ at $90^{\circ} \mathrm{C}$ in solvent-free conditions.

TABLE 3: Optimization amount of Kaolin/Ag nanocomposite catalyst for the synthesis of $\mathbf{4 a}$.

\begin{tabular}{lcc}
\hline Entry & Catalyst & Yield $^{\mathrm{a}}(\%)$ \\
\hline 1 & - & - \\
2 & 0.0005 & 57 \\
3 & 0.0008 & 83 \\
4 & 0.001 & 98 \\
\hline${ }^{\mathrm{a}}$ Reaction conditions: 60 min at $90^{\circ} \mathrm{C}$ in solvent-free conditions.
\end{tabular}

In order to determine the optimum quantity of Kaolin/Ag nanocomposite, the reaction of benzaldehyde, kojic acid, and indole was carried out at solvent-free conditions using different quantities of Kaolin/Ag nanocomposite (Table 3). Kaolin/Ag nanocomposite of $0.001 \mathrm{~g}$ gave an excellent yield in 75 min (Table 3, entry 4).

The above reaction was also examined in various solvents (Table 4). The results indicated that different solvents affected the efficiency of the reaction. Most of these solvents required a longer time and gave moderate yields, and the best results were obtained when solvent-free was used (Table 4, entry 6).

To study the scope of the reaction, a series of aromatic aldehydes, indoles, and kojic acid catalysed by Kaolin/Ag nanocomposite as catalyst were examined. The results are shown in Table 5. In all cases, aromatic aldehyde substituted with either electron-donating or electron-withdrawing groups underwent the reaction smoothly and gave products in good yields.
TABLE 4: Effect of the solvent on the synthesis of $\mathbf{4 a}$ by Kaolin/Ag nanocomposite catalyst.

\begin{tabular}{lcc}
\hline Entry & Solvent & Yield $^{\mathrm{a}}(\%)$ \\
\hline 1 & EtOH & 60 \\
2 & $\mathrm{THF}$ & 20 \\
3 & $\mathrm{H}_{2} \mathrm{O}$ & 45 \\
4 & $n$-Hexane & 10 \\
5 & Toluene & 50 \\
6 & Solvent-free & 98 \\
\hline
\end{tabular}

${ }^{\mathrm{a}} 60 \mathrm{~min}$ at reflux temperature in $10 \mathrm{~mL}$ solvent.

${ }^{\mathrm{b}} 60 \mathrm{~min}$ at $90^{\circ} \mathrm{C}$.

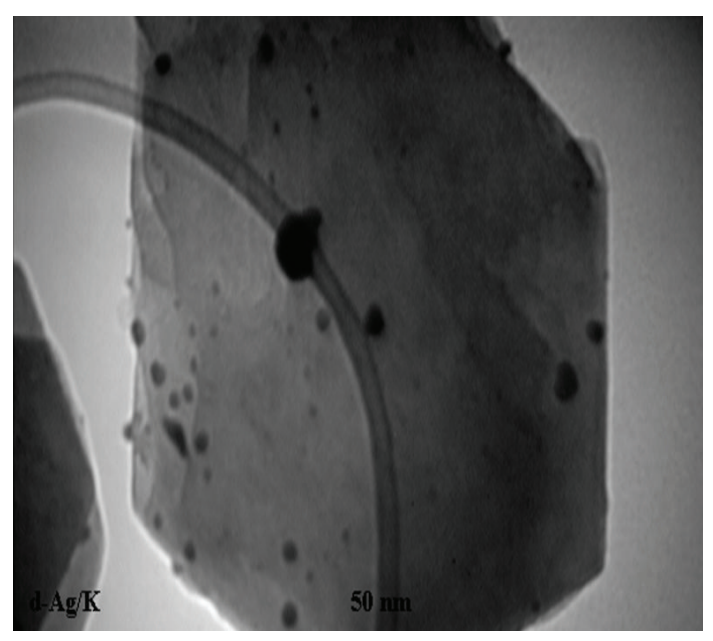

FIgURE 5: TEM image of Kaolin/Ag NPs $50 \mathrm{~nm}$.

The compounds $\mathbf{4 a - f}$ were characterized by their ${ }^{1} \mathrm{H}$ NMR and IR spectroscopy and elemental analyses. Spectral data were compared with the literature data [18].

Compounds $\mathbf{4 g - \mathbf { m }}$ was new and their structures were deduced by elemental and spectral analyses. The mass spectrum of compound $\mathbf{4 h}$ showed the molecular ion peak at 361. The ${ }^{1} \mathrm{H}$ NMR spectrum of $\mathbf{4 h}$ exhibits three sharp lines at $\delta=5.65,6.29$, and $6.63 \mathrm{ppm}$ for the proton of methine and olefinic protons, respectively. The ${ }^{1} \mathrm{H}-\mathrm{NMR}$ 
TABLE 5: Condensation of aromatic aldehyde, kojic acid, and indole derivatives in the presence of Kaolin/Ag nanocomposite catalyst.

\begin{tabular}{|c|c|c|c|c|c|c|}
\hline Entry & Aldehyde & Indole & Product $^{\mathrm{a}}$ & $\begin{array}{l}\text { Time } \\
(\mathrm{min})\end{array}$ & Yield $(\%)^{b}$ & $\begin{array}{c}\text { M.p. } \\
\left({ }^{\circ} \mathrm{C}\right) \text { [Ref.] }\end{array}$ \\
\hline 1 & & & $4 a$ & 60 & 98 & $79-81[18]$ \\
\hline 2 & & & $4 b$ & 65 & 83 & $96-98$ [18] \\
\hline 3 & & & $4 c$ & 55 & 87 & $89-90$ [18] \\
\hline 4 & & & $4 d$ & 60 & 92 & $86-88$ [18] \\
\hline 5 & & & $4 e$ & 75 & 82 & $96-98$ [18] \\
\hline 6 & & & $4 f$ & 70 & 90 & $96-98$ [18] \\
\hline 7 & & & $4 \mathrm{~g}$ & 60 & 92 & $87-89$ \\
\hline 8 & & & $4 h$ & 65 & 90 & Oil \\
\hline 9 & & & $4 i$ & 75 & 82 & $87-89$ \\
\hline 10 & & & $4 j$ & 90 & 85 & $169-171$ \\
\hline 11 & & & $4 k$ & 80 & 80 & $172-174$ \\
\hline 12 & & & 41 & 87 & 82 & $167-169$ \\
\hline 13 & & & $4 m$ & 90 & 85 & $170-172$ \\
\hline
\end{tabular}

${ }^{\mathrm{a}}$ All the products were identified by ${ }^{1} \mathrm{H}$ NMR and ${ }^{13} \mathrm{C}$ NMR spectra and also by comparing of melting point and ${ }^{1} \mathrm{H}$ NMR spectra with those of authentic samples reported in the literature.

${ }^{\mathrm{b}}$ Yields refer to isolated products.

spectrum of compound $\mathbf{4 h}$ exhibited protons of methylene at $4.21 \mathrm{ppm}$ and protons of methyl group at $\delta=2.32$. Three single signals are observed at $10.19,7.43$, and $5.92 \mathrm{ppm}$ that disappeared after the addition of a few drops of $\mathrm{D}_{2} \mathrm{O}$ to $\mathrm{CDCl}_{3}$ solution of compound $\mathbf{4 h}$. These signals are related to $\mathrm{OH}$ and $\mathrm{NH}$ protons. Multiplets are observed between
6.70 and $7.35 \mathrm{ppm}$ which are related to aromatic protons. The ${ }^{13} \mathrm{C}$-NMR spectrum of compound $4 \mathrm{~h}$ showed 20 signals in agreement with the proposed structure. The IR spectrum of compound $4 \mathrm{~h}$ also supported the suggested structure.

An interesting feature of this method is that the reagent can be regenerated at the end of the reaction and can be 


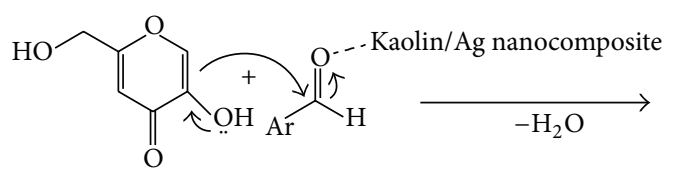

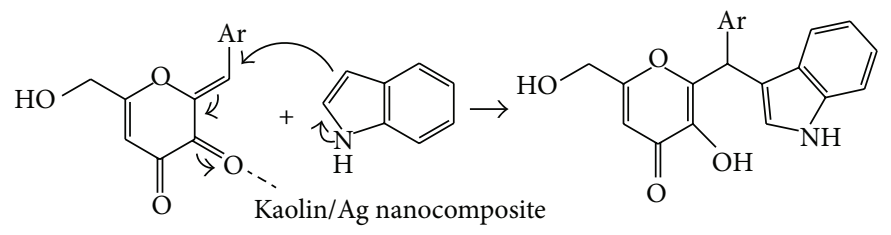

Scheme 2: Proposed mechanism for 2-substituted aryl (indolyl) kojic acid synthesis.

TABLE 6: Recycling studies of reaction between benzaldehyde, kojic acid, and indole in the presence of Kaolin/Ag nanocomposite to give product $\mathbf{4 a}$.

\begin{tabular}{lccc}
\hline Entry & Cycle & Time $(\mathrm{min})$ & Yield $\%^{\mathrm{a}}$ \\
\hline 1 & Fresh & 60 & 98 \\
2 & 1 & 60 & 92 \\
3 & 2 & 60 & 89 \\
4 & 3 & 60 & 85 \\
\hline
\end{tabular}

${ }^{a}$ Yields refer to isolated products.

used several times without losing its activity. To recover the catalyst, after completion of the reaction, the mixture was filtered, catalyst (Kaolin/Ag nanocomposite) was washed with $\mathrm{CHCl}_{3}$, and then the solid residue was dried. This process repeated for three cycles, and the yield of product $\mathbf{4 a}$ did not change significantly (Table 6).

A mechanistic route is suggested for the generation of 2-substituted aryl (indolyl) kojic acid derivatives from the reaction of an aromatic aldehyde, kojic acid, and indole derivatives in the presence of Kaolin/Ag nanocomposite and role of Kaolin/Ag nanocomposite shown as the catalyst in this proposed mechanism (Scheme 2). The initiation step of this chain process begins with the interaction of aldehyde and Kaolin/Ag nanocomposite. The subsequent reaction between the activated aldehyde and kojic acid takes place with the formation of the enone. The resulting enone may undergo Michael's addition with indole to give the desired product as depicted in Scheme 2.

\section{Conclusion}

In summary, by adsorption phase nanoreactor technique, Kaolin/Ag nanocomposite material is synthesized and has shown that it has advantages in the preparation of 2substituted aryl (indolyl) kojic acid derivatives such as shorter reaction times and simple workup and affords excellent yield. The present method does not involve any hazardous organic solvent. Therefore, this procedure could be classified as green chemistry.

\section{Acknowledgments}

The authors gratefully acknowledge the financial support from the Research Council of Islamic Azad University of Yazd, University of Mazandaran, Razi Metallurgical Research Center, and Fluka Company.

\section{References}

[1] F. G. Ramos Filho, T. J. A. Mélo, M. S. Rabello, and S. M. L. Silva, "Thermal stability of nanocomposites based on polypropylene and bentonite," Polymer Degradation and Stability, vol. 89, no. 3, pp. 383-392, 2005.

[2] K. Wang, L. Chen, J. Wu, M. L. Toh, C. He, and A. F. Yee, "Epoxy nanocomposites with highly exfoliated clay: mechanical properties and fracture mechanisms," Macromolecules, vol. 38, no. 3, pp. 788-800, 2005.

[3] J. B. Silva, C. F. Diniz, R. M. Lago, and N. D. S. Mohallem, "Catalytic properties of nanocomposites based on cobalt ferrites dispersed in sol-gel silica," Journal of Non-Crystalline Solids, vol. 348, pp. 201-204, 2004.

[4] M. Díaz, F. Barba, M. Miranda, F. Guitián, R. Torrecillas, and J. S. Moya, "Synthesis and antimicrobial activity of a silverhydroxyapatite nanocomposite," Journal of Nanomaterials, vol. 2009, Article ID 498505, 6 pages, 2009.

[5] L. Balogh, D. R. Swanson, D. A. Tomalia, G. L. Hagnauer, and A. T. McManus, "Dendrimer-silver complexes and nanocomposites as antimicrobial agents," Nano Letters, vol. 1, no. 1, pp. $18-21,2001$.

[6] M. R. Kim, D. K. Lee, and D.-J. Jang, "Facile fabrication of hollow Pt/Ag nanocomposites having enhanced catalytic properties," Applied Catalysis B, vol. 103, no. 1-2, pp. 253-260, 2011.

[7] S. Egger, R. P. Lehmann, M. J. Height, M. J. Loessner, and M. Schuppler, "Antimicrobial properties of a novel silver-silica nanocomposite material," Applied and Environmental Microbiology, vol. 75, no. 9, pp. 2973-2976, 2009.

[8] G. W. Gribble, "Recent developments in indole ring synthesismethodology and applications," Journal of the Chemical Society, Perkin Transactions 1, no. 7, pp. 1045-1075, 2000.

[9] W.-N. Xiong, C.-G. Yang, and B. Jiang, "Synthesis of novel analogues of marine indole alkaloids: mono(indolyl)-4-trifluoromethylpyridines and bis(indolyl)4-trifluoromethylpyridines as potential anticancer agents," Bioorganic and Medicinal Chemistry, vol. 9, no. 7, pp. 1773-1780, 2001.

[10] M.-Z. Piao and K. Imafuku, "Convenient synthesis of aminosubstituted pyranopyranones," Tetrahedron Letters, vol. 38, no. 30, pp. 5301-5302, 1997. 
[11] X. Xiong and M. C. Pirrung, "Modular synthesis of candidate indole-based insulin mimics by claisen rearrangement," Organic Letters, vol. 10, no. 6, pp. 1151-1154, 2008.

[12] B. Sadeghi, A. Hassanabadi, and S. Bidaki, "Synthesis of nanoparticles silica supported sulfuric acid $\left(\mathrm{NPs} \mathrm{SiO}_{2}-\mathrm{H}_{2} \mathrm{SO}_{4}\right)$ : a solid phase acidic catalyst for one-pot synthesis of $4 \mathrm{H}$ chromene derivatives," Journal of Chemical Research, vol. 35, no. 11, pp. 666-668, 2011.

[13] M. Khazaei, M. Anary-Abbasinejad, A. Hassanabadi, and B. Sadeghi, "ZnO nanoparticles: an efficient reagent, simple and one-pot procedure for synthesis of highly functionalized dihydropyridine derivatives," E-Journal of Chemistry, vol. 9, no. 2, pp. 615-620, 2012.

[14] B. Sadeghi, A. Namakkoubi, and A. Hassanabadi, " $\mathrm{BF}_{3} \cdot \mathrm{SiO}_{2}$ nanoparticles: a solid phase acidic catalyst for efficient onepot Hantzsch synthesis of 1, 4-dihydropyridines," Journal of Chemical Research, vol. 37, no. 1, pp. 11-13, 2013.

[15] B. Sadeghi, S. Zavar, and A. Hassanabadi, "Monolayer-protected silver nanoparticles: an efficient and versatile reagent for the synthesis of 3, 4-dihydropyrimidine-2-(1H)-ones (thiones)," Journal of Chemical Research, vol. 36, no. 6, pp. 343-346, 2012.

[16] B. Sadeghi and M. Ghasemi Nejad, "Silica sulfuric acid: an ecofriendly and reusable catalyst for synthesis of benzimidazole derivatives," Journal of Chemistry, vol. 2013, Article ID 581465, 5 pages, 2013.

[17] R. Patakfalvi, A. Oszkó, and I. Dékány, "Synthesis and characterization of silver nanoparticle/kaolinite composites," Colloids and Surfaces A, vol. 220, no. 1-3, pp. 45-50, 2003.

[18] B. V. S. Reddy, M. R. Reddy, C. Madan, K. P. Kumar, and M. S. Rao, "Indium(III) chloride catalyzed three-component coupling reaction: a novel synthesis of 2-substituted aryl(indolyl)kojic acid derivatives as potent antifungal and antibacterial agents," Bioorganic and Medicinal Chemistry Letters, vol. 20, no. 24, pp. 7507-7511, 2010. 

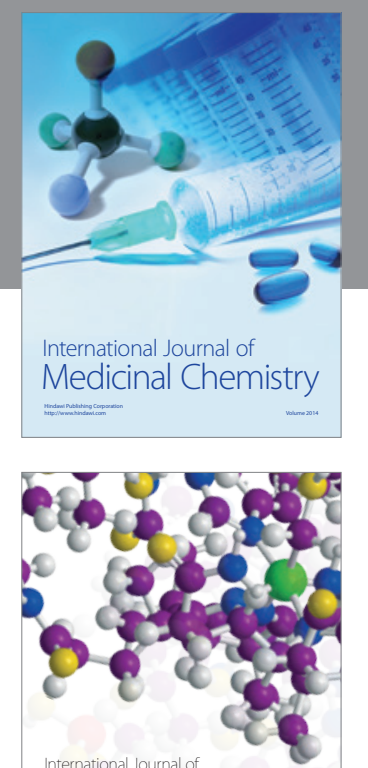

\section{Carbohydrate} Chemistry

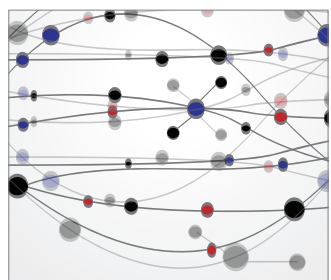

The Scientific World Journal
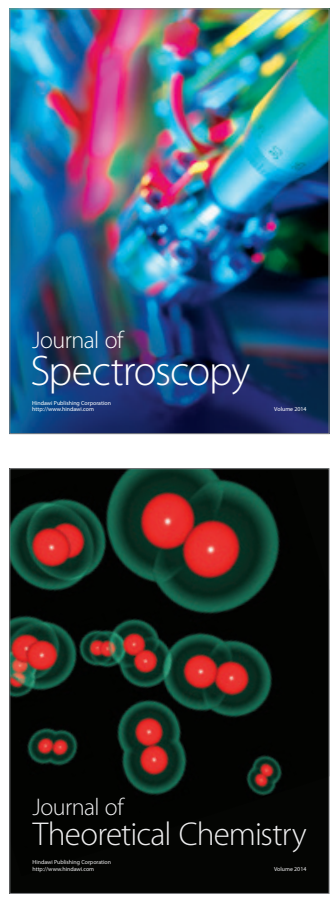
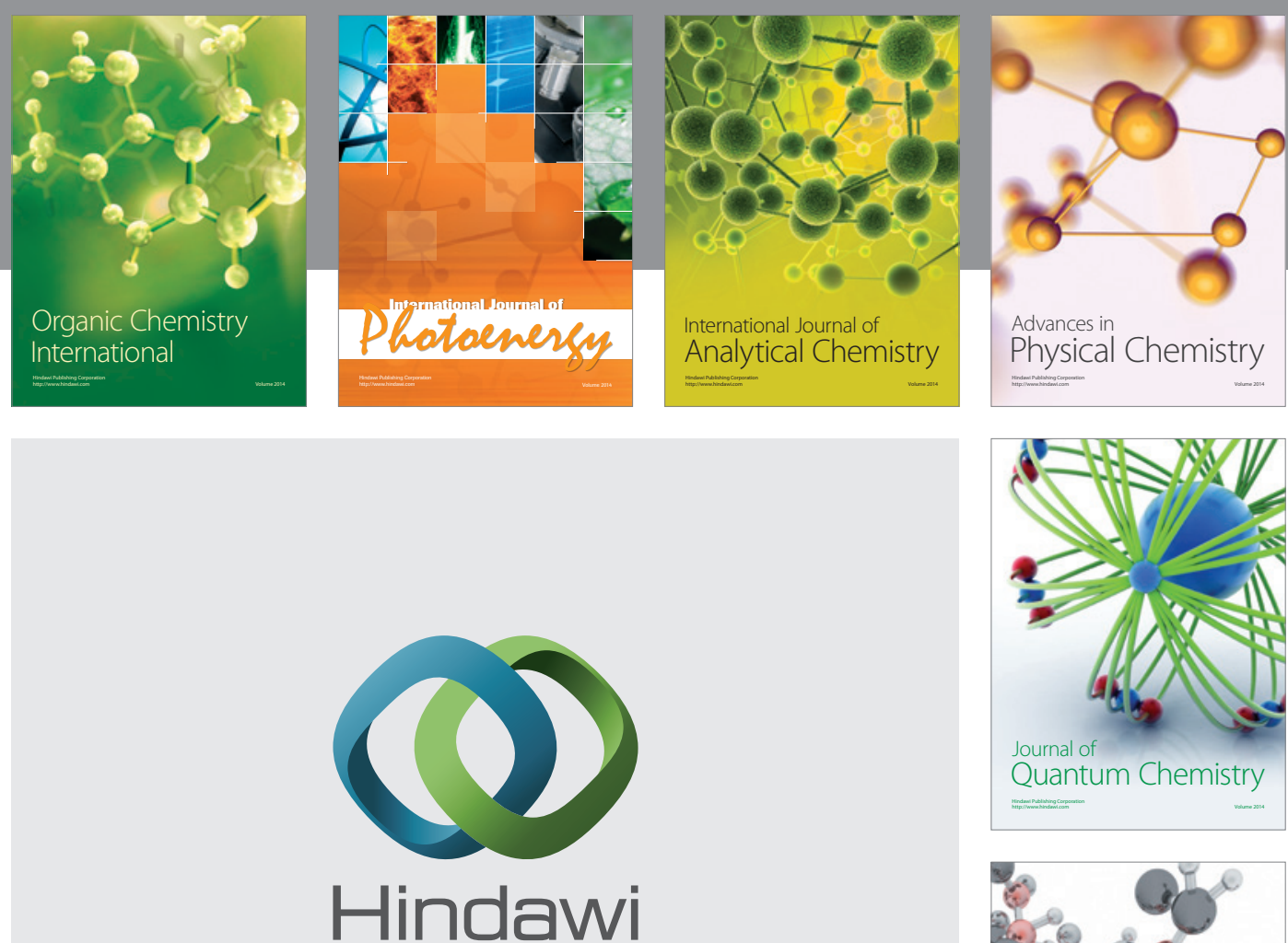

Submit your manuscripts at

http://www.hindawi.com

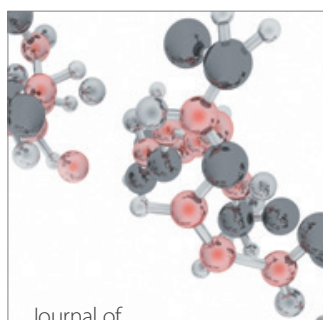

Analytical Methods

in Chemistry

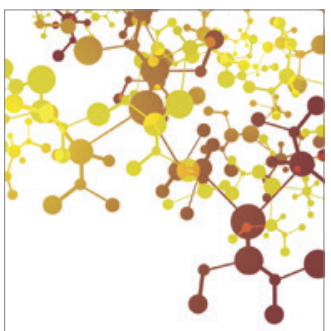

Journal of

Applied Chemistry

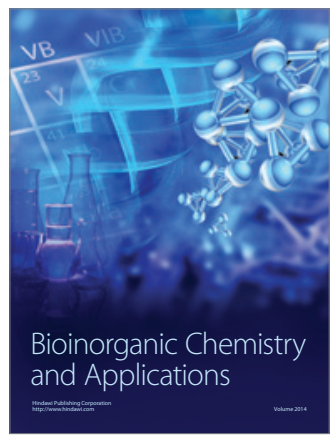

Inorganic Chemistry
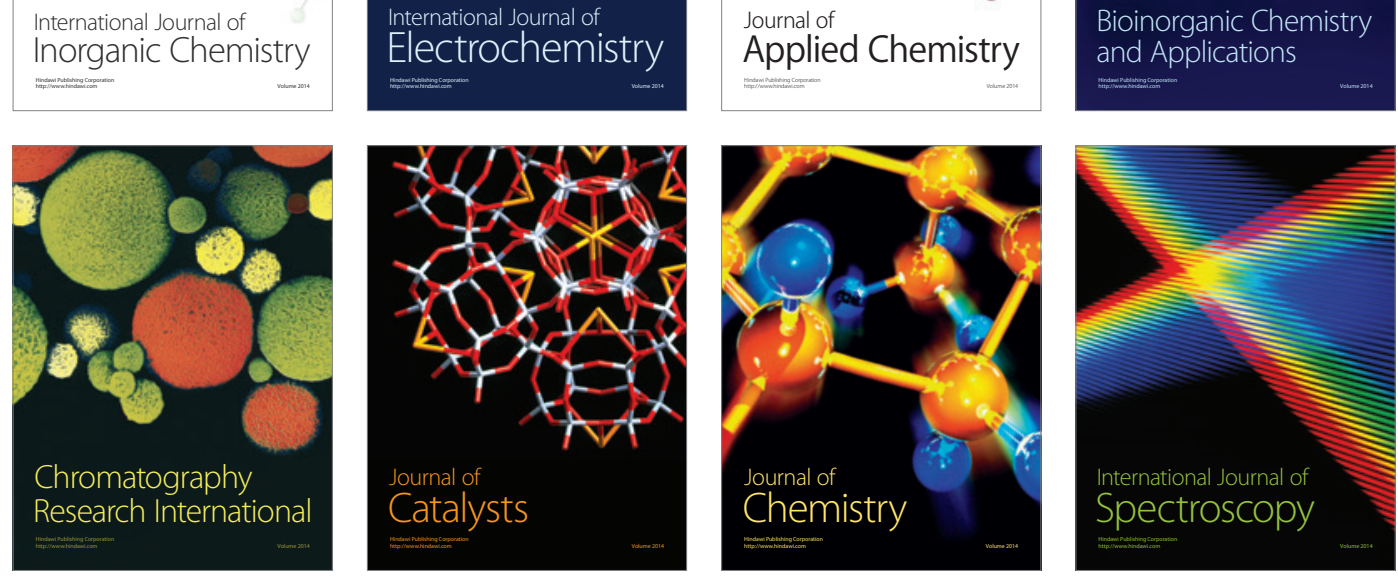